\title{
UPAYA ASEAN DALAM MENGHADAPI SKEMA LIBERALISASI E-COMMERCE DI ASEAN-6 (2015 - 2017)
}

\author{
Miftahur Rahman \& Makmur Keliat \\ Universitas Indonesia, Depok, Indonesia \\ Email : miftahur.nabire@gmail.com
}

\begin{abstract}
ABSTRACK
This study discusses about digital era marked by the advancement of knowledge and innovation in the field of Technology, Information and Communication (ICT) which has provided major changes to all aspects of life, especially in economy. ASEAN as a regional cooperation in the Southeast Asia region, currently as an emerging market in e-commerce competition, especially for Singapore, Malaysia, Thailand, Indonesia, the Philippines and Vietnam (ASEAN-6). Based on this phenomenon, my research question is, how are ASEAN-6's efforts in facing of ecommerce liberalization in the digital era in line with the ASEAN framework (AEC Blueprint 2015 \& 2025, ASEAN ICT Masterplan and ASEAN Digital Integration). This research use the theory of trade liberalization, the concept of economic integration and the concept of digital economics to be able to examine the phenomenon of e-commerce liberalization in ASEAN-6. The various literature reviewed by the author shows that the growth of e-commerce is influenced by four factors, namely: 1) internet infrastructure; 2) electronic payment system; 3) shipping services that has a wide coverage; 4) government policy framework in each ASEAN-6 country. In addition, there are several obstacles found including: 1) the geographical location of each ASEAN-6 country that affects the process of developing the internet infrastructure; 2) issues of personal data protection and cyber security related to electronic payment systems; 3) effectiveness and efficiency of the existence of shipping services, especially shipping between countries; and 4) policy discrepancies between countries. This study concludes that as a regional organization in Southeast Asia, ASEAN continues to strive to harmonize regulations among member countries, form a framework of cooperation and other agendas to be able to harmonize the development of ICT, especially the growth of ecommerce. The fundamental difference from this study with previous studies is that there have been no studies that examine e-commerce liberalization in the ASEAN region, so the author tries to collaborate on several facts related to the growth of e-commerce liberalization in ASEAN-6
\end{abstract}

Keywords: ASEAN, e-commerce, digital economy, economic integration

\section{PENDAHULUAN}

Arus globalisasi yang kita kenal saat ini ditandai dengan kemajuan dan integrasi dalam berbagai bidang; informasi, komunikasi, transportasi, dan terknologi, yang kemudian menjadikan pola hubungan internasional semakin luas. Selain itu istilah globalisasi sangat erat kaitannya dengan perubahan sifat ketergantungan antar-bangsa maupun antar-masyarakat dalam berinteraksi di dunia internasional (Chandler, 2009). Interaksi dan ketergantungan yang dilakukan oleh berbagai aktor dalam kancah internasional bisa berbentuk sebuah investasi, perdagangan, jasa dan barang serta bentuk interaksi lainnya yang semakin menjadikan batas dari sebuah negara semakin bias.

Selanjutnya keberadaan aktor yang bergerak dalam pola interaksi politik ataupun ekonomi pun tidak hanya sebatas aktor negara. Para pelaku bisnis, investor, ataupun kepala perusahaan atau biasa disebut dengan Chief Executive Officer (CEO) perusahaan dan pedagang serta pelaku ekomoni lainnya bisa menjadi aktor non-negara yang memiliki pengaruh besar 
terhadap timbulnya jaringan baru dalam pola interaksi ekonomi. Pola interaksi ekonomi antaraktor (negara dan non-negara) dalam ruang lingkup kerja sama internasional telah menciptakan sebuah kondisi ekonomi global, kondisi inilah yang kemudian dikenal sebagai "Globalisasi Ekonomi." Globalisasi dalam bidang perekonomian diartikan sebagai suatu proses interaksi ekonomi dan perdagangan dari setiap masyarakat internasional yang ada menciptakan sebuah kondisi perekonomian global dan menciptakan sebuah pasar yang terintegrasi (Winarno, 2008). Kemajuan dari globalisasi ekonomi sangat erat kaitannya dengan tiga faktor pendorong; 1) kemunculan kaum kapitalis global atau biasa dikena dengan perusahaan manca negara (Multi National Corporation, MNC) yang ada disetiap belahan dunia, 2) perkembangan ilmu pengetahuan dan teknologi, 3) keberadaan dari negara-negara berkembang yang mendukung atas aksi ekspansi kaum kapitalis global tersebut (Prawironegoro, 2006).

Kemudahan dalam melakukan praktek ekonomi telah dirasakan oleh seluruh kalangan dari para konsumen, produsen, pemilik modal juga investor. Berbagai data, berita, informasi seputar produk, perusahan, kondisi politik lintas negara ASEAN telah tersaji secara lengkap dan bebas dalam jaringan internet (daring). Munculnya e-commerce yang selaras dengan pertumbuhan internet di beberapa negara ASEAN memberikan kemudahan bagi para pengguna baik produsen maupun konsumen. Para konsumen mendapatkan kemudahan dalam mendapatkan informasi, mendapatkan barang, jasa dan kebutuhan lain tanpa harus berkunjung ke negara tujuan. Di sisi lain, para produsen dapat memasarkan produknya dengan bebas di beberapa tempat (market place) tanpa harus memikirkan biaya operasional seperti periklanan, keamanan, sewa tempat, dan lain sebagainya.

Di era digital yang semakin berkembang pesat, ASEAN sebagai institusi regional di Asia Tenggara mencoba membangun sebuah skema khusus dalam rangka menghadapi perkembangan TIK, sebuah perkembangan yang secara langsung maupun tidak langsung memiliki dampak pada dinamika ekonomi digital khususnya perkembangan e-commerce. Skema ini diatur dalam 4 (empat) pilar utama Masyarakat Ekonomi ASEAN yang terangkum dalam ASEAN Economic Community Blueprint (AEC Blueprint 2015, 2025). Selain AEC Blueprint 2015 dan 2025, agenda lain ataupun kerangka kerja yang dibentuk untuk menghadapi perkembangan digital adalah kerangka kerja e-ASEAN (e-ASEAN Framework) yang dibentuk pada tahun 2000, ASEAN Information, Communication and Technology Masterplan 2015 (AIM 2015), ASEAN Digital Integration serta beberapa kesepakatan yang dihasilkan dalam ASEAN Telecommunications and IT Ministers Meeting (TELMIN) dan ASEAN Telecommunications and Information Technology Senior Officials Meeting (TELSOM) (ASEAN, 2019). 


\section{KERANGKA ANALISIS}

Penelitian ini menggunakan beberapa teori dan konsep yang diharapkan bisa menjadi acuan dalam membedah, menganalisa dan memperdalam permasalahan yang diangkat sehingga dapat menjawab pertanyaan penelitian.

Konsep free trade, investment, dan technology sangatlah dibutuhkan keberadaannya untuk bisa menguatkan sebuah negara ataupun perusahaan dalam proses distribusi produksi antar-negara. Perdagangan bebas yang juga mengadopsi pemikiran dari trade liberalitation yang sudah diterapkan di setiap bentuk dalam bentuk kerja sama perekonomian internasional. Sistem ini sangat menjunjung tinggi pemberlakuan sistem non-tariff barriers, sebuah sistem perdagangan internasional yang tidak memberlakukan tarif pada kegiatan ekspor-impornya. Negara anggota yang masuk ke dalam sebuah lembaga kerja sama ekonomi dunia akan mendapatkan keringanan dalam biaya pendistribusian barang. Biaya pajak yang diterapkan akan memengaruhi tinggi dan rendahnya suatu harga barang, sehingga semakin tinggi penerapan pajak akan menyebabkan harga barang menjadi semakin tinggi begitu pula sebaliknya, vise versa. Konsep perdagangan bebas merupakan sebuah perwujudan kesepakatan antar negara untuk menjalin kerja sama internasional, yakni General Agreement of Tariffs and Trade (GATT) yang dibentuk pada tahun 1947 (Yanai, 2004).

Keberadaan pasar global merupakan sebuah wadah yang dapat memfasilitasi persaingan antar aktor, oleh karena itu ciri utama dari pasar global adalah adanya integrasi dan keterkaitan antar satu aktor dengan aktor lainnya. Aktor-aktor yang bermain di dalamnya pun tidak hanya sebatas antar negara, terjadi beberapa hubungan yang saling memperngaruhi satu sama lain. Pertama hubungan tradisional antar negara, kedua hubungan negara dengan pasar global dan ketiga adalah hubungan antara individu dengan negara (Rudy, 2003). Intergrasi ini memaksa setiap negara untuk bisa lebih produktif dalam menghadapi globalilsasi agar tidak tergerus dengan negara lain yang menjadi pesaingnya. Iklim perdagangan bebas inilah yang kemudian menjadikan iklim persaingan dari setiap perusahaan semakin bervariasi. Selanjutnya, dibutuhkan keberadaan pemerintah sebagai institusi yang menopang persaingan industri lokal untuk selalu meningkatkan daya saing, memberikan motivasi bagi sektor usaha dan bisnis demi terciptanya pertumbuhan industri nasional.

Konsep lain yang menjadi dasar dari penulisan ini adalah konsep ekonomi digital. Hingga saat ini belum ada definisi baku yang menjelaskan ekonomi digital, oleh karena itu penulis akan mengambil salah satu konsep ekonomi digital dari Don Tapscott. Don Tapscott 
adalah orang yang pertama kali memperkenalkan sebuah konsep ekonomi digital pada tahun 1994 dan dijelaskan dalam bukunya yang berjudul The Digital Economy; Promise and Peril in the Age of Networked Intellegence yang pertama diterbitkan pada Mei, 1997 (Tapscott, The Digital Economy, 1997). Konsep ekonomi digital yang kita kenal saat ini tidak terlepas dari penggunaan TIK dalam setiap aspek kegiatan ekonomi seperti transaksi, produksi, pemasaran, penjualan, pertukaran infromasi dan aspek lainnya. Oleh karena itu, perkembangan ekonomi digital sangatlah dipengaruhi oleh perkembangan TIK, atau sebuah bentuk fenomena baru dari kegiatan ekonomi maupun bisnis yang dalam pelaksanaannya sangatlah dibantu dengan keberadaan internet.

Don Tapscott menyebutkan ada 12 tema atau karakteristik yang menjadi faktor penopang terbentuknya sebuah ekonomi digital. 12 tema tersebut diantaranya (Tapscott, Twelve Themes of The New Economy, 2015); Knowledge, Digitization, Virtualization, Molecularization, Internetworking, Disintermediation, Convergence, Innovation, Prosumption, Immediacy, Globalization dan Discordance. Secara singkat tema-tema tersebut dapat dijelaskan sebagai berikut;

1. Knowledge (ilmu pengetahuan)

Ilmu pengetahuan adalah dasar dari terbentuknya sebuah bentuk ekonomi digital atau yang disebutkan oleh Don Tapscott sebagai bentuk ekonomi baru (new economy). Dengan kemajuan TIK ini pula terciptalah sebuah kecerdasan buatan (artificial intellegence-AI) yang terus dikembangkan di berbagai perusahaan.

\section{Digitization (digitalisasi)}

Digitalisasi merupakan sebuah proses yang merubah bentuk fisik ke dalam kumpulan bilangan biner (binary number). Sebagai contoh dari bentuk digitalisasi adalah revolusi pengiriman surat kertas menjadi surat elektronik (electronic mail, e-mail), media cetak menjadi media elektronik dan informasi lainnya yang saat ini telah berubah ke dalam bentuk digital.

3. Virtualization (virtualisasi)

Virtualisasi merupakan revolusi dari bentuk fisik ke bentuk virtual (dapat ditampilkan menggunakan perangkat lunak). Untuk lebih mudah memahami bentuk dari virtualisasi adalah perubahan sistem pembayaran tunai yang saat ini berubah menjadi uang virtual, perubahan dari toko fisik ke toko virtual dalam konsep e-commerce juga merupakan bentuk dari virtualisasi di era ekonomi digital.

4. Molecularization (mudah beradaptasi dengan kondisi terbaru) 
Perkembangan TIK bergerak sangat cepat, dinamis dan tidak dapat dibendung. Dalam kondisi ini, perusahaan atau pelaku bisnis yang tidak dapat beradaptasi dengan lingkungan sekitar akan hilang dengan sendirinya.

5. Integration/Internetworking (integrasi atau jaringan yang salih terhubung)

Ciri lain yang menandai kegiatan ekonomi digital adalah adanya keterkaitan antara satu dengan lainnya. Secara singkat Tapscott menyebut sebagai hubungan antara aktifitas inti (core activity) dengan aktifitas penunjang (supporting activity).

6. Disintermediation (disintermediasi, ketiadaan batas)

Di era digital ekonomi, penghubung yang menjembatani antara produsen dengan konsumen cenderung hilang karena konsumen dapat langsung berkomunikasi dengan produsen, begitu juga sebaliknya.

7. Convergence (menyatukan beberapa kunci utama dalam ekonomi)

Kemampuan pelaku bisnis atau perusahaan untuk menyatukan tiga aspek komputerisasi, komunikasi dan konten (computing, communication, content). Ketiga aspek inilah yang harus dimiliki oleh pelaku bisnis di era digital agar dapat bersaing secara global.

8. Innovation (inovasi)

Penyebaran informasi yang semakin mudah dari satu tempat ke tempat lainnya tentu menjadikan ide atau temuan baru dapat dengan mudah ditiru oleh pelaku bisnis lainnya terutama para pesaing (competitor). Oleh karena itu, ekonomi digital sangatlah bergantung pada inovasiinovasi baru yang terus dihadirkan oleh setiap pelaku bisnis.

9. Prosumption

Konsumen dapat sekaligus menjadi produsen saat melakukan transaksi ekonomi digital, begitu pula produsen yang juga dapat menjadi konsumen. Sebagai contoh adalah di era dot.com yang memungkinkan pengguna internet (konsumen) menciptakan sebuah domain atau menjual domain kepada orang lain, dalam hal ini konsumen telah produsen.

10. Immediacy (kesegeraan)

Proses yang cepat dan tepat dalam memproduksi sebuah barang merupakan bentuk dari ekonomi digital. Proses yang cepat ini didukung dengan adanya pertukaran data elektronik (electronic data interchange, EDI) yang dapat menghubungkan antara produsen dengan konsumen di seluruh penjuru dunia.

11. Globalization

RIR | Volume 1, Nomor 2, 2019 
Tapscott menyebutkan "The new economy is a global economy". Kegiatan ekonomi global tidak akan lepas dari perdagangan barang, jasa, modal, pekerja dan informasi. Globalisasi yang tidak mengenal batas wilayah dan kedaulatan menjadikan praktek ekonomi digital semakin berkembang cepat.

\section{Disordance}

Dampak siginifikan dari ekonomi digital adalah perbedaan kelas antara masyarakat yang memiliki akses penuh terhadap perkembangan TIK dengan masyarakat yang tidak memiliki akses, tidak memiliki pengetahuan ataupun motivasi untuk menggunakan TIK dalam aspek kehidupan sehari-hari.

Dari ke-12 karakteristik yang telah disebutkan oleh Tapscott di atas menunjukkan bahwa fenomena ekonomi digital memiliki cakupan yang luas dan tidak terbatas, dari industri hiburan, elektronik, otomotif, pendidikan, kesehatan, perbankan ataupun finansial, hingga ruang lingkup lainnya yang saat ini belum dapat dijangkau oleh ekonomi klasik. Terlebih lagi bahwa perkembangan TIK yang menjadi faktor penopang ekonomi digital yang tidak dapat dibendung dan akan terus berkembang setiap waktu.

Berkaitan dengan konsep integrasi ekonomi, tujuan pembentukan kerja sama ekonomi dalam suatu wilayah tidak lain adalah untuk mewujudkan ekonomi kawasan yang terintegrasi. Integrasi ekonomi inilah yang diharapkan mampu membantu pertumbuhan ekonomi disebuah kawasan. Bela Balassa memperkenalkan sebuah teori integrasi ekonomi (Balassa, 1961). Teori ini menjelaskan mengenai beberapa tahapan dalam proses kerja sama dan integrasi ekonomi regional yang ada disuatu wilayah. Tahapan tersebut adalah sebagai berikut: 1) TPA atau Trade Preferency Arrangement; 2) FTA atau Free Trade Area; 3) CU atau Customs Union; 4) CM atau Common Market; 5) EU atau Economic Union, 6) MU atau Monetary Union. Melihat pada tahapan integrasi ekonomi yang diungkapkan oleh Balassa di atas, kita melihat bahwa saat ini ASEAN telah mencapai pada tahap ke lima yakni Common Market. Artinya, berbagai kerja sama yang dilakukan antar negara anggota ASEAN dalam skema perdagangan bebas ASEAN (ASEAN Free Trade Area) telah menunjukkan bahwa ASEAN berupaya memberikan berbagai fasilitas kepada setiap negara anggotanya untuk dapat bekerja sama dengan negara anggota lain demi kemajuan ekonomi domestik dan ekonomi regional.

Melihat dari beberapa literatur yang ada, penulis merangkum bahwa perkembangan TIK memengaruhi seluruh aspek kehidupan kita saat ini, tidak terkecuali berdampak pada pertumbuhan ekonomi digital. Secara singkat dapat diartikan bahwa ekonomi digital merupakan sebuah kegiatan jual-beli yang dibantu menggunakan TIK yang terbarukan. Sebagai salah contoh 
adalah perbedaan ojek pangkalan dengan ojek yang dibantu dengan kemajuan TIK atau ojek online. Pelaku usaha dan konsumen tidaklah mengalami perubahan besar, namun proses bisnislah yang kemudian berubah karena dibantu dengan kemajuan TIK. Proses pemesanan, pembayaran, hingga penerimaan barang yang dipesan melalui kurir online kini dapat dilakukan secara online. Metrik berikut akan mencoba memberikan gambaran dan pemahaman mengenai bentuk ekonomi digital, khsusunya yang ada di ASEAN-6.

Tabel 1 Ruang Lingkup Proses Bisnis Ekonomi Digital di ASEAN-6

\begin{tabular}{|c|c|}
\hline E-commerce & $\begin{array}{l}\text { Lazada, Blibli, JD.id, Zalora, Lazada, Zilingo, Matahari } \\
\text { Mall, i-Lotte, Jakmall, Carrousel, eBay, Bukalapak, } \\
\text { Tokopedia, Shopee, Blanja.com, }\end{array}$ \\
\hline $\begin{array}{l}\text { Perjalanan Online } \\
\text { (Online Travel) }\end{array}$ & $\begin{array}{c}\text { Airbnb, Agoda, Expedia, AsiaTravel, TravelCube } \\
\text { Booking.com, Traveloka, Tiket.com, }\end{array}$ \\
\hline Pembayaran Elektronik & $\begin{array}{c}\text { BCA, Mandiri, Visa, MasterCard, UOB, Standard } \\
\text { Chartered, HSBC, Digibank, American Express } \\
\text { Paypal, JCB, } \\
\text { DANA, AkuLaku, Ovo, Kredivo }\end{array}$ \\
\hline Logistik & $\begin{array}{c}\text { Cj Logistics, Singapore Express, AliExpress, DHL, TnT, } \\
\text { FedEx, JNE, JnT, TIKI, Ninja Van, Sicepat, }\end{array}$ \\
\hline $\begin{array}{l}\text { Transportasi Online } \\
\text { (Ride-Hailing) }\end{array}$ & Gojek, Grab, Uber \\
\hline
\end{tabular}

Sumber: Analisa Penulis dari rangkuman berbagai literatur

\section{METODE PENELITIAN}

Penelitian ini menggunakan metode penelitian kualitatif dengan teknik deskriptif analisis. Pendekatan yang digunakan dalam penelitian ini adalah pendekatan deduktif yang akan menjelaskan fenomena umum dari dinamika perkembangan ekonomi digital kemudian merujuk kepada pembahasan khusus terkait beberapa strategi yang dilakukan oleh organisasi regional ASEAN dalam menghadapi pertumbuhan e-commerce di era digital. Teknik pengumpulan dan analisis data dalam penelitian ini menggunakan teknik studi pustaka. Data yang diperoleh dalam penelitian ini adalah berupa data sekunder yang didapatkan penulis dari beberapa sumber data seperti:

- $\quad$ Buku-buku, jurnal-junal, majalah, koran lokal dan juga internasional. 
- Data-data tertulis yang berbentuk elektronik berupa e-book dan website dan informasi elektronik lainnya yang dapat membantu penulis dalam proses pengumpulan data sekunder sesuai dengan topik pembahasan.

\section{PEMBAHASAN}

Liberalisasi perdagangan selalu menjunjung tinggi sebuah skema untuk membebaskan berbagai hambatan (tariff-barriers) dalam proses perdagangan internasional. Liberalisasi ekonomi, khususnya liberalisasi perdagangan akan terus berupaya mengurangi bahkan menghilangkan hambatan perdagangan di sektor jasa, barang dan arus investasi. Sejalan dengan yang disebutkan oleh Gilpin yang menyebutkan bahwa liberalisasi perdagangan akan membahwa dampak positif bagi setiap negara yang menerapkan konsep liberalisasi perdagangan ataupun turut serta dalam kerja sama internasional (Gilpin, 2001, pp. 198-199).

Beberapa keuntungan yang didapatkan dengan menerapkan liberalisasi perdagangan adalah terciptanya sebuah iklim kompetisi di pasar domestik, menciptakan sebuah persaingan harga yang kompetitif, dan memberikan banyak pilihan bagi para konsumen untuk mendapatkan produk yang diinginkan dengan harga terendah. Lebih jauh Gilpin menyebutkan bahwa perdagangan bebas akan menjadikan sebuah negara dapat memilih spesialisasi sektor (baik barang ataupun jasa) yang dirasakan lebih unggul untuk kemudian menjadi produk ekspor dan memilih produk-produk tertentu untuk diimpor. Singkatnya, dengan adanya perdagangan bebas setiap negara akan mendapatkan keuntungan komparatif dari proses produksi di masing-masing negara yang tergabung dalam kerjamasa bilateral ataupun kerja sama multilateral. Jika semua proses tersebut berjalan dengan baik, maka tujuan akhir dari proses perdagangan dan kerja sama internasional adalah tercapainya sebuah perdamaian dunia (Gilpin, 2001).

Sebuah konsep liberalisasi perdangan yang pertama kali dibentuk adalah General Agreement on Tariffs and Trade (GATT) yang disusun pada tahun 1947 dan ditandatangani oleh 80 negara dengan tingkat nilai expor tertinggi pada saat itu (Baldwin \& Kay, 1975). Konsep GATT ini kemudian diresmikan pada tahun 1948 yang kemudian dikenal dengan Havana Charter sebagai sebuah skema sistem perdagangan multilateral pertama di dunia yang telah mencapai kesepakatan bersama (Baldwin \& Kay, 1975). Seiring dengan perkembangan ekonomi dari beberapa negara di berbagai kawasan, sistem perdagangan internasional kemudian berkembang kepada pendekatan regional/kawasan (regional economic cooperation) ataupun berdasarkan pada skala ekonomi (economic scale) yang memiliki tujuan akhir untuk mengintegrasikan sebuah kawasan (regional integration) (Baldwin \& Kay, 1975). 
Lebih lanjut Baldwin (1975) menyebutkan bahwa pembentukan organisasi kawasan berdasarkan skala ekonomi merupakan sebuah upaya dari negara-negara berkembang untuk dapat bersaing dengan pasar internasional. Sebagai contoh pembentukan organisasi berskala ekonomi seperti Latin America Free Trade Association (LAFTA) yang dibentuk pada 1960, Maghreb Group (Algeria, Morocco dan Tunisia) pada tahun 1964 dan ASEAN (Malaysia, Filippina, Singapura, Thailand dan Indonesia) pada tahun 1967 merupakan organisasi yang dibentuk berdasarkan pada kondisi ekonomi negara anggota. Selain itu, negara-negara tersebut juga belajar dari kesuksesan sebuah organisasi kawasan di Eropa pada saat itu yakni European Economic Community (Baldwin \& Kay, 1975, p. 108).

Keberadaan e-commerce yang berpotensi menumbuhkan PDB sebuah negara juga disampaikan oleh Google \& Temasek. Hasil dari laporan penelitian yang dilakukan oleh Google \& Temasek menunjukkan bahwa pertumbuhan pengguna ekonomi internet di kawasan Asia Tenggara pada tahun 2015 dapat berpotensi menumbuhkan kondisi ekonomi kawasan sebanyak 50 miliyar dolar AS pada tahun 2017. Sektor ekonomi internet yang dimaksudkan dalam penelitian ini adalah; 1) ride-hailing (transportasi online) sebanyak US\$ 2,5 M, 2) media pemasaran elektronik menyumbang sebanyak US\$ 3,7 M, 3) agen/jasa perjalanan online US\$ 19,1 M dan 4) e-commerce yang mencapai angka US\$ 5,5 M. Melalui empat sektor ekonomi internet tersebut, pertumbuhan ekonomi internet di kawasan Asia Tenggara diproyeksikan akan terus bertambah hingga 200 miliar dolar AS pada tahun 2025 (Google \& Temasek, 2016).

Berkaitan dengan fenomena pertumbuhan e-commerce di kawasan ASEAN, menurut laporan yang ditunjukkan oleh Google dan Temasek, ASEAN-6 merupakan negara dengan persentase pertumbuhan e-commerce tercepat dibanding negara ASEAN lainnya (Google \& Temasek, 2016). Pertumbuhan e-commerce di Asia Tenggara khususnya di negara ASEAN-6 telah mengalami peningkatan yang sangat signifikan. Hal tersebut telah dijelaskan dalam data yang di paparkan sebelumnya yang menunjukkan bahwa pertumbuhan ekonomi dan perkembangan e-commerce di ASEAN-6 semakin meningkat dari setiap tahunnya. Beberapa hal yang menjadi faktor penunjang dari perkembangan e-commerce diantaranya:

a. infrastruktur internet,

b. munculnya metode pembayaran baru secara online (e-payment)

c. pertumbuhan logistik, serta

d. kerangka kebijakan yang dimiliki masing-masing negara, khususnya sebuah kerangka kebijakan yang disiapkan untuk menyikapi kemunculan e-commerce. 
Dari beberapa faktor yang memengaruhi perkembangan e-commerce di ASEAN-6 inilah yang kemudian akan menjadi pembahasan selanjutnya.

\section{A. Infrastruktur internet}

World Bank pada Gambar 3.2 di atas mengenai indeks pertumbuhan TIK di negara ASEAN-6 pada tahun 2015 menunjukkan bahwa dari negara ASEAN-6, Singapura merupakan negara dengan indeks pertumbuhan TIK tertinggi dengan nilai pertumbuhan internet sebanyak 7.90 (skala 0-100), diikuti dengan Malaysia, Thailand, Vietnam dan Filipina, sedangkan Indonesia masih berada pada tingkat paling rendah dari indeks pertumbuhan TIK yang hanya mencapai 3.60 dari skala 0-100. Jika digambarkan berdasarkan urutan, dari 175 negara, Singapura menduduki peringkat ke-19, Malaysia peringkat ke-66, Thailand peringkat ke-79, Vietnam peringkat ke 104, Filipina peringkat ke-106 dan terkahir adalah Indonesia yang masih mendudukin peringkat ke-115 dari 175 negara lainnya (World Bank, 2019). Dari data tersebut kita dapat melihat bahwa keberadaan internet di ASEAN-6 belum merata antara satu negara dengan negara lainnya. Hal ini dapat disebabkan oleh faktor demografi maupun faktor geografis yang berbeda dari masing-masing negara. Sebagai contoh Indonesia yang memiliki indeks pertumbuhan TIK paling rendah dari yang lainnya.

Dari data tersebut kita dapat melihat bahwa keberadaan internet di ASEAN-6 belum merata antara satu negara dengan negara lainnya. Hal ini dapat disebabkan oleh faktor demografi maupun faktor geografis yang berbeda dari masing-masing negara. Sebagai contoh Indonesia yang memiliki indeks pertumbuhan TIK paling rendah dari yang lainnya. Jika dibandingkan dengan Malaysia ataupun Singapura, tentu Indonesia masih mengalami berbagai kendala untuk meningkatkan infrastruktur internet ke setiap wilayah karena terhambat luas wilayah yang terpisah oleh lautan, gunung-gunung serta hutan. Oleh karena itu dibutuhkan cara khusus agar pemerataan internet di Indonesia dapat diwujudkan dengan mudah (Indotelko, 2017).

Tabel 1 Indeks Inklusi Internet di ASEAN-6 2017 (dalam \%)

\begin{tabular}{lccccc}
\hline Negara & $\begin{array}{c}\text { Ketersediaan } \\
\text { (Availability) }\end{array}$ & $\begin{array}{c}\text { Keterjangkauan } \\
\text { (Affordability) }\end{array}$ & $\begin{array}{c}\text { Relevansi } \\
\text { (Relevance) }\end{array}$ & $\begin{array}{c}\text { Kesiapan } \\
\text { (Readiness) }\end{array}$ & Overall \\
\hline Singapura & 92,7 & 83,7 & 87,4 & 76,0 & $\mathbf{8 7 , 3}$ \\
Malaysia & 68,2 & 79,1 & 87,2 & 77,7 & $\mathbf{7 6 , 2}$ \\
Thailand & 73,3 & 85,5 & 73,8 & 59,5 & $\mathbf{7 5 , 7}$ \\
Vietnam & 64,6 & 73,7 & 90,2 & 77,3 & $\mathbf{7 3 , 7}$ \\
Indonesia & 64,2 & 71,3 & 63,3 & 74,2 & $\mathbf{6 7 , 2}$
\end{tabular}




\begin{tabular}{cccccc} 
Filipina & 63,0 & 62,8 & 68,1 & 69,3 & $\mathbf{6 4 , 6}$ \\
\hline & Rata-rata & & $\mathbf{7 4 , 1}$ \\
\hline
\end{tabular}

Sumber: The Economist TEIU, 2017, telah diolah kembali

B. Sistem pembayaran elektronik

Data yang dipaparkan oleh Capgemini dan BNP PARIBAS dalam World Payment Report 2018 menyebutkan bahwa rata-rata persentase petumbuhan penggunaan sistem pembayaran online pada tahun 2015-2016 di kawasan ASEAN telah mencapai 20\%. Tidak hanya ASEAN-6, karena jika melihat pada pertumbuhan pembayaran di kawasan lain, pertumbuhan transaksi non-tunai tersebut juga dialami di kawasan lain seperti Europa, Timur Tengah dan Afrika (CEMEA) yang mengalami pertumbuhan sebanyak 17,1\% serta negara berkembang di ASIA mencapai 25.2\%. Bila dibandingkan dengan rata-rata pertumbuhan global, pada tahun 2016, pertumbuhan transaksi non-tunai pada tahun 2016 mencapai 10\% dan mencapai 483 milyar USD. Beberapa negara yang mengalami tingkat pertumbuhan transaksi non-tunai terbesar adalah Rusia (36.5\%), Cina yang mencapai 26\% (Capgemini \& BNP Paribas, 2018).

Di Indonesia, Filipina, Thailand, dan Vietnam, dua hal yang menjadi perhatian khusus adalah keamanan dan dapat diandalkan (kepercayaan). Oleh karena itu, pembayaran di tempat masih menjadi pilihan utama untuk melakukan transaksi. Di beberapa negara, tingkat transaksi yang menggunakan sistem pembayaran di tempat (COD) mencapai 50-70\% dari total pesanan yang dikirimkan. Sedangkan di Malaysia, mayoritas masyarakat telah melakukan pembayaran lintas batas dengan menggunakan sistem pembayaran non-tunai (selain COD).

C. Keberadaan jasa pengiriman antar negara

Di era perdagangan bebas saat ini, tidak jarang bahwa proses bisnis maupun transaksi jual-beli di e-commerce yang kita temui sudah berskala regional bahkan internasional. Sebagai contoh saat kita melakukan transaksi pembelian barang di salah satu situs e-commerce, dari beberapa barang tersebut kita mendapatkan informasi mengenai keberadaan barang yang kita beli merupakan barang yang dikirim dari luar negeri (track and trace). Informasi tersebut juga menjelaskan bahwa harga barang yang dibeli sudah termasuk bea cukai ekspor-impor.

Di lain sisi, fenomena dari peningkatan arus barang dan manusia (skilled labour) secara langsung akan memengaruhi pertumbuhan dan inovasi para perusahaan logistik/jasa ekspedisi itu sendiri. Selain itu, dengan adanya kemunculan dan perkembangan perusahaan logistik yang semakin pesat, secara tidak langsung juga akan menimbulkan persaingan usaha melalui 
bertambahnya perusahaan logistik baik swasta maupun milik negara. Perusahaan logistik mulai memasuki pasar jasa agar dapat bersaing untuk mendapatkan kepercayaan masyarakat di tingkat regional maupun internasional (logistic competence).

D. Kerangka kebijakan pemerintah untuk menyikapi e-commerce

Berkaitan dengan upaya ASEAN dalam menghadapi era digital global, ASEAN memiliki beberapa pendekatan serta langkah strategis untuk mempersiapkan masyarakat ASEAN yang berbasis TIK. Oleh karena itu, diperlukan peran serta pemerintah untuk merumuskan kebijakan yang sesuai dengan kondisi di masing-masing negara, kebijakan tersebut dapat mencakup proses pembangunan infrastruktur, proses dalam menyiapkan Sumber Daya Manusia yang kompeten di bidang ekonomi digital, serta kebijakan untuk menciptakan sebuah ruang ataupun ekosistem bagi para perusahaan yang bekerja di bidang TIK. Dari beberapa rencana kebijakan tersebut maka hal ini akan sejalan dengan rancangan dalam AEC Bluprint 2015 berkaitan pendekatan strategis.

Agenda prioritas yang direncakan dalam AEC Blueprint tersebut menjelaskan bahwa kesepakatan yang ada dalam AEC Blueprint 2015 dalam menghadapi pertumbuhan e-commerce mewajibkan bagi setiap negara anggota ASEAN untuk merencanakan undang-undang atau membentuk sebuah regulasi khusus. Oleh karena itu, upaya mengembangkan e-commerce di era digital global tentunya membutuhkan sebuah pendekatan strategis serta rencana aksi (action plan). Beberapa upaya yang dilakukan ASEAN menjadi agenda prioritas bagi setiap negara anggota, upaya ini bertujuan untuk memberikan kemudahan bagi setiap negara anggota ASEAN agar dapat menyelaraskan undang-undang terkait perkembangan TIK di era digital. Secara keseluruhan, negara ASEAN-6 telah memiliki aturan ataupun kebijakan khusus yang dirancang untuk menghadapi perkembangan TIK khususnya kemunculan e-commerce. Sejalan dengan Gery Hawke, bahwa pertumbuhan TIK yang mengarah kepada integrasi kawasan haruslah diimbangi dengan aturan yang kuat. Dari Tabel 3 di bawah, hal ini menunjukkan bahwa dari aspek hukum ataupun kebijakan, negara ASEAN-6 telah memiliki kesiapan dalam menghadapi pertumbuhan ekonomi di era digital.

Tabel 3 Metrik Kebijakan Pemerintah ASEAN-6 Tahun 2017

\begin{tabular}{lcccc}
\hline & Pembayaran & Perlindungan & $\begin{array}{c}\text { Perlindungan } \\
\text { Privasi dan Data }\end{array}$ & Keamanan \\
& Elektronik & Konsumen & Konsumen & Siber \\
\hline Indonesia & $\sqrt{ }$ & $\sqrt{ }$ & $\sqrt{ }$ & $\sqrt{ }$ \\
Malaysia & $\sqrt{ }$ & $\sqrt{ }$ & $\sqrt{ }$ & $\sqrt{ }$ \\
Singapura & $\sqrt{ }$ & $\sqrt{ }$ & $\square *$ & $\sqrt{ }$ \\
Thailand & $\sqrt{ }$ & &
\end{tabular}




\begin{tabular}{lllll} 
Filipina & $\sqrt{ }$ & $\sqrt{ }$ & $\sqrt{ }$ \\
Vietnam & $\sqrt{ }$ & $\sqrt{ }$ & $\sqrt{ }$ & $\sqrt{ }$ \\
\hline
\end{tabular}

Keterangan: $\sqrt{ }=$ sudah ada dan diterapkan, $\square=$ dalam proses perancangan

* pada bulan Mei tahun 2018, Menteri Sosial dan Ekonomi Digital Thailand telah mempublikasikan rancangan akhir dari Kebijakan Perlindungan Data Pribadi (Baker McKenzie, 2018).

Sumber: ADB \& ESCAP, 2018. Analisa penulis, telah diolah kembali,

Proses pembentukan kebijakan yang ditujukan untuk menghadapi pertumbuhan ecommerce di era digital ini dapat dianalisa menggunakan konsep pembentukan kebijakan pemerintah oleh Kauppi dan Viotti (Kauppi, 2009). Konsep pembentukan kebijakan pemerintah yang dipaparkan oleh Viotti \& Kauppi menyebutkan adanya dua faktor penting yang memengaruhi proses pembentukkan kebijakan, kondisi domestik dan kondisi internasional (faktor internal dan eksternal). Kondisi domestik yang dimaksudkan di sini adalah fenomena pertumbuhan UMKM atau pelaku usaha lain yang semakin ditopang dengan kemajuan TIK. Tingginya tingkat konsumsi masyarakat dan perubahan perilaku masyarakat yang lebih mengarah kepada transaksi elektronik. Sedangkan kondisi internasional (eksternal) adalah fenomena pertumbuhan e-commerce, khususnya e-commerce mancanegara yang sudah menjangkau pasar regional (multinational corporation) seperti Alibaba, Aliexpress, Amazon, Lazada, Shopee, Grab, JD.com dan e-Bay (Ecommerce Germany, 2019).

Perjalanan ASEAN untuk mencapai kawasan yang terintegrasi telah melalui proses yang panjang, berbagai kerja sama serta kerangka kerja dipersiapkan untuk mewujudukan kawasan yang terintegrasi baik secara ekonomi, politik, maupun budaya. Keinginan ASEAN untuk terus mewujudkan integrasi ini dimanifestasikan ke dalam beberapa persetujuan yang dihasilkan dari berbagai pertemuan. Hal ini dibuktikan dengan pembentukan ASEAN Vision 2020 pada tahun 1997, 10 tahun kemudian ASEAN mulai dengan pembentukan ASEAN Community 2020 yang kemudian dipercepat menjadi ASEAN Economic Community 2015 pada tahun 2007 dan mulai diberlakukan pada tahun 2008. Serta pada tahun 2010, upaya integrasi kawasan ditunjukkan dengan dibentuknya Masterplan on ASEAN Connectivity (ASEAN Secretariat, 2017).

Beberapa upaya yang dilakukan ASEAN dalam rangka menghadapi fenomena ekonomi digital dan liberalisasi e-commerce dapat dilihat melalui beberapa strategi yang telah dilakukan oleh ASEAN. Upaya tersebut bertujuan untuk memastikan bahwa setiap negara anggota ASEAN sudah memiliki kerangka khusus dalam menghadapi pertumbuhan e-commerce, baik dalam negeri maupun e-commerce yang hadir dari luar negeri. Agenda-agenda yang dilakukan ASEAN 
juga menjadi salah satu pertimbangan bagi setiap negara anggota dalam menentukan kebijakan nasionalnya. Penulis melihat bahwa selain AEC Blueprint 2015 \& 2025, ada berbagai agenda turunan dari AEC Blueprint tersebut. Agenda lain yang berhubungan dengan fenomena perkembangan ekonomi digital di ASEAN tersebut diantaranya; 1) Kerangka kerja e-ASEAN, 2) ASEAN ICT Masterplan 2015 \& 2020, dan 3) ASEAN Digital Integration Framework.

\section{Kerangka kerja e-ASEAN}

Dibentuk pada tanggal 22-25 November, 2000, e-ASEAN merupakan sebuah kesepakatan yang tidak lain adalah untuk menghadapi arus globalisasi di era digital (ASEAN, 2000). Beberapa pokok pembahasan yang ada di dalamnya adalah; a) menciptakan sebuah kerja sama yang dapat mengembangkan, menguatkan dan meningkatkan sektor TIK di kawasan ASEAN, b) membentuk sebuah kerja sama untuk mengurangi tingkat kesenjangan digital pada masingmasing negara anggota ASEAN, c) menciptakan sebuah kesepakatan ataupun kerja sama yang antar sektor publik dengan sektor swasta, d) mempromosikan sebuah liberalisasi perdagangan khususnya perdagangan produk TIK.

\section{ASEAN ICT Masterplan $2015 \& 2020$}

ASEAN ICT Masterplan (AIM) 2015 dan 2020 merupakan hasil kesepakatan dari agenda pertemuan TELMIN ke 10 dan ke 15. Oleh karena itu, struktur pemerintahan dalam AIM 2015 dikepakati oleh TELMIN yang bertugas untuk mengeluarkan formulasi kebijakan. Dalam proses perumusan kebijakan tersebut, TEMIN dibantu oleh TELSOM dan ASEAN Telecommunication's Regulator Council (ATRC). Sedangkan ASEAN Secretariat bertugas sebagai koordinator utama untuk setiap hasil kesepakatan dan ASEAN ICT Centre bertugas untuk mengawasi segala bentuk operasionalisasi dari proses implementasi program yang telah disepakati bersama (ASEAN Secretariat, 2015).

\section{ASEAN Digital Integration Framework}

Kemampuan negara ASEAN untuk terus menumbuhkan perekonomian telah dibuktikan dengan tingkat persentase pertumbuhan ekonomi yang semakin meningkat di setiap tahunnya. Pada tahun 2015, ASEAN merupakan sebuah kawasan dengan tingkat pertumbuhan ekonomi yang mencapai 2,4 miliyar dollar AS. Jika dibandingkan dengan pertumbuhan ekonomi global, ASEAN berada pada peringkat ke enam setelah Amerika Serikat, Cina, Jepang, Jerman dan United Kingdom dan Perancis yang menduduki urutan ke tujuh. Sedangkan dari segi pertumbuhan ekonomi di kawasan Asia sendiri, ASEAN merupakan sebuah kawasan yang menduduki peringkat ke tiga dengan tingkat pertumbuhan ekonomi sebanyak 5,2\% dalam kurun waktu tahun 2007 hingga 2015 (ASEAN Secretariat, 2016). 
Ironisnya, meskipun ASEAN merupakan kawasan dengan rata-rata pertumbuhan ekonomi yang stabil baik secara global maupun di tingkat regional namun ASEAN masih belum dapat memaksimalkan potensi perkembangan ekonomi digital yang dimiliki oleh setiap negara anggota ASEAN (Florian Hoppe, 2018, p. 2). Pemanfaatan TIK sebagai sarana utama dalam melakukan kegiatan ekonomi oleh seluruh masyarakat ASEAN masih belum optimal jika dibandingkan dengan Cina, Amerika dan Eropa, karena ekonomi digital ASEAN hanya menyumbang sebanyak 7\% dari total PDB (Florian Hoppe, 2018). Kurangnya ASEAN dalam memaksimalkan perkembangan ekonomi digital ini menjadi tantangan besar bagi ASEAN sendiri sebagai organisasi regional dan juga menjadi pekerjaan rumah tersendiri bagi setiap negara anggota ASEAN. Untuk menghadapi hal ini, ASEAN membentuk sebuah skema khusus sebagai pemicu bagi seluruh masyarakat ASEAN agar dapat memaksimalkan dan memanfaatkan perkembangan TIK di berbagai sektor.

Disebutkan dalam perjanjian ADI pada bagian pendahuluan paragraf ke tiga bahwa beberapa aspek penting yang disepakati dalam ASEAN Digital Integration Framework merupakan elemen/aspek penting yang sejalan dengan pilar-pilar AEC Blueprint 2025, ASEAN ICT Masterplan 2020, Masterplan on ASEAN Connectivity 2025, ASEAN Framework for Personal Data Protection, serta ASEAN Strategic Action Plan for SME Development 2025 (ASEAN.org, 2019). Hal ini bertujuan agar setiap negara anggota ASEAN mendapatkan kemudahan dalam menyusun kebijakan dan mengaplikasikan berbagai agenda yang disepakati bersama. Sehingga setiap agenda yang masuk dalam kategori agenda prioritas (priority areas) dapat dicapai oleh masing-masing negara anggota ASEAN.

\section{KESIMPULAN}

Sebagai organisasi regional, ASEAN terus berupaya untuk menjadi katalisator akan pertumbuhan dunia digital. Penyusunan agenda serta pembahasan mengenai pertumbuhan ecommerce dimanfestasikan ke dalam bentuk AEC Blueprint 2015 \& 2025 yang ditungkan ke dalam pilar "Competitive Economic Region". Pilar ini mengandung agenda khusus yang membahas mengenai upaya ASEAN dalam mengembangkan kondisi e-commerce dan upaya ASEAN dalam menghadapi berbagai faktor penunjang pertumbuhan ekonomi yang ditopang oleh keberadaan e-commerce. Selain AEC Blueprint, agenda ASEAN lainnya seperti e-ASEAN, hasil kesepakatan dalam ASEAN TELSOM dan TELMIN, ASEAN Digital Integration Framework, serta ASEAN ICT Masterplan juga merupakan bentuk keseriusan ASEAN dalam menghadapi kehadiran TIK di berbagai aspek kehidupan yang semakin berkembang. 
Analisis dalam penelitian ini menunjukkan bahwa adanya keterkaitan antara konsep liberalisasi perdagangan dengan agenda ASEAN dalam mengintegrasikan kawasan melalui skema ASEAN Economic Community. Konsep liberalisasi perdagangan yang menjadikan hambatan tarif dan non-tarif sebagai faktor penentu kesuksesan liberalisasi perdagangan internasional juga dapat ditemui di agenda ASEAN dalam menghadapi pertumbuhan ekonomi digital (e-commerce). Pilar AEC Blueprint 2015 terkait free flow of foods, free flow of capital dan free flow of skilled labour menunjukkan bahwa salah satu agenda yang dilakukan ASEAN adalah menggunakan pendekatan strategis. Dalam pendekatan strategis tersebut dicantumkan upaya ASEAN untuk mengurangi hambatan tarif dan non-tarif (elimination of tariff) melalui skema Common Effective Preferential Tariffs-ASEAN Free Trade Area (CEPT-AFTA).

Perkembangan liberalisasi e-commerce tentunya tidak terlepas dari dukungan empat faktor yang menjadi landasan utama atas kesuksesan e-commerce di ASEAN-6. Empat faktor tersebut diantaranya adalah: 1) perkembangan infrastruktur internet yang disertai dengan keberadaan pengguna internet yang semakin bertambah, 2) keberadaan sistem pembayaran elektronik yang lebih efektif dan efisien serta memudahkan pengguna untuk melakukan transaksi online, 3) pertumbuhan jasa pengiriman (logistik) yang semakin bervariatif, efisien dan sesuai dengan permintaan pengguna, 4) berbagai kerangka kebijakan yang dimiliki oleh masing-masing negara anggota ASEAN-6, tentunya sebuah kerangka kebijakan yang diharapkan mampu membantu dan melindungi para pelaku bisnis agar dapat terus bersaing di tingkat domestik, regional maupun tingkat internasional.

Selain itu, perkembangan ekonomi digital melalui pertumbuhan e-commerce juga memunculkan masalah baru seperti perlindungan data diri, kemanan dalam bertransaksi, dan kemunculan kejahatan siber. Bila ASEAN dapat menetapkan sebuah standarisasi kebijakan di setiap anggotanya serta menetapkan standarisasi terkait pemberlakuan pajak yang berhubungan dengan transaksi e-commerce maka potensi perkembangan ekonomi digital di ASEAN akan menjadi salah satu faktor penunjang pertumbuhan ekonomi kawasan dan mendorong proses integrasi kawasan.

Melihat dampak yang signifikan dari perkembangan TIK di setiap tahun dan masih sedikitnya penelitian dibidang e-ecommerce atau ekonomi digital maka penulis memiliki beberapa saran rekomendasi untuk penelitian selanjutnya. Dari temuan-temuan yang dipaparkan pada penelitain, penulis memberikan rekomendasi agar penelitian selanjutnya dapat lebih memfokuskan pembahasan kepada dampak e-commerce terhadap berbagai bidang studi sosial, dan ekonomi politik internasional maupun keamanan internasional. Oleh karena itu, penelitian 
selanjutnya diharapkan dapat meneliti informasi data diri pengguna e-commerce juga dapat memengaruhi keamanan non-tradisional suatu negara, khususnya negara tempat e-commerce itu berada. Sedangkan dari bidang studi ekonomi politik internasional, penulis melihat berbagai studi literatur yang mengkaji fenomena perkembangan dompet digital (e-wallet) serta pengaruh uang elektronik (e-money) terhadap kebijakan domestik dan internasional. Penelitian selanjutnya diharapkan dapat meneliti bagaimana perkembangan metode pembayaran non-tunai atau online yang didorong oleh pertumbuhan e-commerce dapat mempercepat proses integrasi kawasan, khususnya ASEAN.

Penelitian ini juga diharapkan dapat memberikan kontribusi kepada Indonesia khususnya bagi para pemangku kebijakan yang terlibat dalam proses pengembangan ekonomi digital. Pihak-pihak yang terlibat seperti Kementerian Komunikasi dan Informatika Republik Indonesia (KOMINFO) yang bertugas menetapkan regulasi mengenai pertumbuhan infrastruktur internet dan isu terkait perlindungan data diri pengguna internet. Hingga saat ini, isu menyangkut fenomena ekonomi digital yang masih menjadi sorotan utama nasional adalah mengenai isu perlindungan data. Peraturan Pemerintah No.82 Tahun 2012 tentang Penyelengaraan Sistem dan Transaksi Elektronik menjadi dasar utama yang menjadi pedoman bagi setiap pemangku kebijakan dalam menghadapi isu tersebut.

Selanjutnya hal yang menjadi tugas pokok adalah bagaimana dan siapa yang akan bertanggung jawab untuk mengatur, mengelola data elektronik yang ada. Berdasarkan informasi yang didapatkan oleh penulis, Kominfo telah merumuskan sebuah lembaga baru yang bertugas untuk melakukan monitoring terhadap para Penyelenggara Sistem Elektronik (PSE)/perusahaan berbasis teknologi yang melakukan aktifitas di Indonesia dan melakukan pengumpulan data.

Dari pihak swasta terdapat Asosiasi Pedagang Ritel Indonesia (APRINDO), Asosiasi Pengusaha Indonesia (APINDO) serta Asosiasi E-Commerce Indonesia (idEA) diharapkan mampu menjadi penghubung dan penyalur aspirasi dari berbagai e-commerce yang ada di Indonesia. Tentunya masih banyak lagi lembaga pemerintah ataupun swasta yang harus dilibatkan dalam proses pembuatan kebijakan yang mengatur aktifitas ekonomi digital di Indonesia. Melalui kebijakan yang selaras serta kemampuan setiap pelaku bisnis dan konsumen dalam memanfaatkan perkembangan TIK akan menjadikan kegiatan ekonomi digital sebagai salah satu sektor yang menyumbang pertumbuhan PDB Indonesia. 


\section{DAFTAR PUSTAKA}

ASEAN. (2000, December 11). Retrieved from e-ASEAN Framework Agreement: https://asean.org/?static_post=e-asean-framework-agreement

ASEAN. (2019, May 24). ASEAN Telecommunications and IT Ministers Meeting (TELMIN).

Retrieved from https://asean.org/asean-economic-community/asean-telecommunicationsand-it-ministers-meeting-telmin/

ASEAN Secretariat. (2015). ASEAN ICT Masterplan 2015 Completion Report. ASEAN, ASEAN Secretariat, Jakarta. Retrieved Mei 20, 2019, from https://www.asean.org/storage/images/2015/December/telmin/ASEAN\%20ICT\%20Compl etion\%20Report.pdf

ASEAN Secretariat. (2016). ASEAN Economic Community at a Glance. Jakarta: The ASEAN Secretariat.

ASEAN Secretariat. (2017). ASEAN Economic Integration Brief. Jakarta: ASEAN.

ASEAN.org. (2019). ASEAN Ditigal Integration Framework. Retrieved Mei 20, 2019, from asean.org: https://asean.org/storage/2019/01/ASEAN-Digital-Integration-Framework.pdf

Baker McKenzie. (2018, September). New draft Personal Data Protection Bill issued for public hearing - Substantial changes following GDPR. Retrieved May 29, 2019, from Baker McKenzie Thailand; Client Alert: http://bakerxchange.com/cv/c5e848a9f09ae47460c31fdecfa434ae69ed0b63

Balassa, B. (1961). The Theory Of Economic Integration. Greeedwood Press.

Baldwin, R. E., \& Kay, D. A. (1975). International Trade and International Relations. International Organization, Vol. 29, No. 1, World Politics and International Economics, 99-100.

Capgemini \& BNP Paribas. (2018). World Payment Report 2018. Capgemini.

Chandler, D. (2009). The Global Ideology: Rethinking the Politics of the 'Global Turn' in IR. Journal of International Relations, 535.

Ecommerce Germany. (2019). Leading Marketplaces in Asia. Retrieved Mei 2019, from Ecommerce Germany News: https://ecommercegermany.com/blog/16-leadingmarketplaces-asia

Florian Hoppe, T. M. (2018, June 08). Advanciing Towards ASEAN Digital Integration. Retrieved from Bain \& Company: https://www.bain.com/insights/advancing-towardsasean-digital-integration/

Gilpin, R. (2001). Global Political Economy: Understanding The International Economic Order. New Jersey: Princeton University Press.

Google \& Temasek. (2016). e-Conomy SEA - Unlocking the $\$ 200$ billion digital opportunity in. Google \& Temasek.

Google \& Temasek. (2016). e-Conomy SEA: Unlocking the \$200B digital opportunity in Southeast Asia. Google \& Temasek. Retrieved June 15, 2019

Indotelko. (2017, December 25). Pemerintah ungkap tantangan pembangunan infrastruktur internet. Retrieved from Indotelko: https://kominfo.go.id/content/detail/12182/pemerintahungkap-tantangan-pembangunan-infrastruktur-internet/0/sorotan_media

Kauppi, P. R. (2009). Interntional Relations and World Politics: Security, Economy and Indentity. New Jersey: Pearson International Edition.

Kemnkeu. (2018, Maret). Media Keuangan. Kesetaraan Pajak Untuk E-Commerce, XIII.

Luo, C. (2018, September 5). E-commerce IQ. Retrieved from Understanding the Upcoming and Current Tax Regulations on Ecommerce in Southeast Asia: https://ecommerceiq.asia/taxregulations-ecommerce-southeast-asia/

Prawironegoro, D. D. (2006). Ekonomi Politik Globalisasi (Kajian Ekonomi Politik, Filsafat, dan Antropologi). Diadit Media. 
Rudy, T. M. (2003). Hubungan Internasional Kontemporer dan Masalah-masalah Global. Bandung: PT. Refika Aditama.

Tapscott, D. (1997). The Digital Economy (1st ed.). McGraw-Hill.

Tapscott, D. (2015). Twelve Themes of The New Economy. In D. Tapscott, The Digital Economy (pp. 54-77). McGraw-Hill.

Winarno, B. (2008). Globalisasi; Peluang atau Ancaman bagi Indonesia. Penerbit Erlangga.

World Bank. (2019, May 19). TCdata360. Retrieved from Country rank and value in the ITU ICT Development Index:

https://tcdata360.worldbank.org/indicators/h2e1ddd20? country=IDN\&indicator=24719\&c ountries=SGP,MYS,THA,VNM,PHL\&viz=bar_chart\&years=2015\&indicators=944

Yanai, A. (2004). Characteristic of APEC trade liberalization; A compare analysis with the WTO. In J. Okamoto, Trade Liberalization and APEC (p. 11). London and New York: Routledge. 